\title{
Temperature Dependence of SilnZnO Thin Film Transistor Fabricated by Solution Process
}

\author{
Sang Yeol Lee ${ }^{\dagger}$, Taehyun Kang, Sang Min Han, and Young Seon Lee \\ Department of Semiconductor Engineering, Cheongju University, Cheonju 360-764, Korea \\ Jun Young Choi \\ Department of Electrical Engineering and Institute for Nano Science, Korea University, Seoul 136-701, Korea
}

Received November 11, 2014; Revised December 4, 2014; Accepted February 11, 2015

Thin film transistor (TFT) with silicon indium zinc oxide (SIZO) was fabricated by solution process, and the effect of annealling temperature on the electrical performance has been explored. The performance of SIZO TFT exhibited saturation mobility of $1.37 \mathrm{~cm}^{2} / \mathrm{Vs}$, a threshold voltage of $-7.2 \mathrm{~V}$, and an on-off ratio of $1.1 \times 10^{5}$.

Keywords: Oxide thin film transistors, SiInZnO, Solution process

\section{INTRODUCTION}

Amorphous oxide semiconductors (AOSs) are promising candidate for the next generation semiconductor materials. Oxide TFT have shown good electrical properties such as high field effect mobility, low subthreshold slope, and high carrier concentration, which were comparable to hydrogenated amorphous silicon (a-Si) TFT.[1-4] Amorphous oxides are composed of heavymetal cations, which constitute attractive compound. However, the presentation of the second metal ion in the main matrix enhances the film's intensity to oxygen that can control electrical properties. [5] Conventional a-Si is inappropriate for large-area ultra-definition (UD) and 3-dimensional (3D) displays, due to low field effect mobility, and it hardly adapts large size display. In the past decade, AOSs have made tremendous improvement in display industry. Traditional deposition process for oxide semiconductor, such as physical vapor deposition (PVD), chemical vapor deposition (CVD), or pulsed laser deposition (PLD) require

${ }^{\dagger}$ Author to whom all correspondence should be addressed: E-mail: sylee@cju.ac.kr

Copyright (C2015 KIEEME. All rights reserved. This is an open-access article distributed under the terms of the Creative Commons Attribution Non-Commercial
License (http:///creativecommons.org/licenses/by-nc/3 0 . $)$ which permits unrestricted noncommercial use, distribution, and reproduction in any medium, provided the original work is property cited.
dited vacuum process, which has high manufacturing cost and lowthroughput.[6-9] Many effort have been reported by high-performance oxide TFTs using solution process which has a simple, low cost, and high throughput. Several solution processes have been developed for oxide semiconductors, such as spin coating, dip coating, and inkjet printing. These characteristics have been used in various device applications, such as flexible displays, transparent displays, and large size display. However, there are still many challenges that impede the field effect mobility due to the trap state. There have been intensive explorations of new multicomponent oxide semiconductor by using solution process. In order to decompose the organic solvent and residual materials, solution process generally needs a high annealing temperature. SIZO TFT shows good transfer characteristics at $300^{\circ} \mathrm{C}$ annealing temperature. Also, silicon metal cations have higher M-O bonding energy $(775 \mathrm{~kJ} / \mathrm{mol})$ than indium $(470 \mathrm{~kJ} /$ mol) and zinc (385 kJ/ mol). [10] Therefore, silicon has an effect on the degeneration of the oxygen vacancy, which is the origin of the majority of the carriers.

In this article, we discussed about the fabrication of TFTs based on a solution process derived from multicomponent SIZO TFTs. We focused on the process temperature of SIZO TFTs. The properties of oxide semiconductors have been realized by controlling the annealing temperature. 


\section{EXPERIMENTAL DETAILS}

In order to create a uniform precursor of SIZO thin films, silicon tetrachloride $\left[\mathrm{SiCl}_{4}\right]$, indium nitrate hydrate $\left[\mathrm{In}\left(\mathrm{NO}_{3}\right)_{3} \cdot \mathrm{XH}_{2} \mathrm{O}\right]$, and zinc acetate dihydrate $\left[\mathrm{Zn}\left(\mathrm{CH}_{3} \mathrm{COO}\right)_{2} \cdot 2 \mathrm{H}_{2} \mathrm{O}\right]$ were mixed into a solvent of 2- methoxyethanol $\left[\mathrm{C}_{3} \mathrm{H}_{8} \mathrm{O}_{2}\right]$ and ethyleneglycol, with a concentration of $0.5 \mathrm{M}$. The mole ratio of In: $\mathrm{Zn}$ was fixed at 1:1, and silicon was added from 0.01 to 0.4 mole. Ethyleneglycol was used as stabilizing agent to improve the solubility of precursor salts. Then, it was stirred at room temperature for $6 \mathrm{~h}$ to form SIZO precursor. The precursor solution was filtered through a $0.5 \mu \mathrm{m}$ syringe filter. The solvent was then spin-coated at 3,000 rpm for $40 \mathrm{~s}$ on the heavily doped p-type silicon wafer. Then, it was placed on a hot plate at $300^{\circ} \mathrm{C}$, in order to improve the active layer adhesion in air condition. Then, it was annealed in vacuum at $300^{\circ} \mathrm{C}$ for $1 \mathrm{~h}$ in the tube furnaces. The SIZO channel was isolated by the wet-etching process, using hydrochloric acid $(\mathrm{HCl})$ for $10 \mathrm{sec}$. The width/length of active channel area was 250/50 $\mu \mathrm{m}$. Finally, Ti/Au of $70 \mathrm{~nm}$ film was deposited for the source and drain electrodes by e-beam evaporator and thermal evaporator. The I-V characteristics were measured with a 4-point semiconductor analyzer, in the dark at room temperature. A diagram of the bottom-gate TFTs fabricated by the solution process in this study is shown in Fig. 1.

\section{RESULTS AND DISCUSSION}

Figure 2 shows the evolution of the I-V characteristics at different process temperatures from As-grown to $300^{\circ} \mathrm{C}$ of solution processed SIZO TFTs. SIZO TFTs shows the enhancement mode device. The threshold voltage was shifted toward negative direction from 7.0 to $2.2 \mathrm{~V}$, when the temperature was increased. This could be explained that the annealing temperature influenced the carrier concentration, and it was not sufficient to decrease the trap state due to organic solvent and residual materials at low temperature. Consecutive post annealing under vacuum enhanced the electrical properties of the TFT, resulting in mobility from $0.009 \mathrm{~cm}^{2}$ to $1.37 \mathrm{~V}^{-1} \mathrm{~s}^{-1} \mathrm{~cm}^{2} \mathrm{~V}^{1} \mathrm{~s}^{-1}$. The excess oxygen vacancy was generated by vacuum annealing. In the $\mathrm{ZnO}$ based oxides systems, free electron were generated that can improved the field effect mobility of TFT. The oxygen vacancies were generated by the following reaction:

$$
O_{o}^{x}=\frac{1}{2} O_{2}(g)+\mathrm{V}_{O}^{\prime \prime}+2 e^{-}
$$

The oxygen atoms could preferentially leave their original sites. The annealing process generated the doubly charged oxygen vacancy. Oxygen vacancy could offer the carriers with two electron [11,12]. In the case of the solution processed films, it was important that the annealing temperature had generated oxygen vacancies when dehydroxylation and condensation occur. [13] The threshold voltage was determined from the conventional linear square root fitting of drain current method, and field effect mobility was calculated from the following equation.

$$
I_{D S}=\frac{\mu_{F E} C_{i} W}{2 L}\left(V_{G S}-V_{t h}\right)^{2}
$$

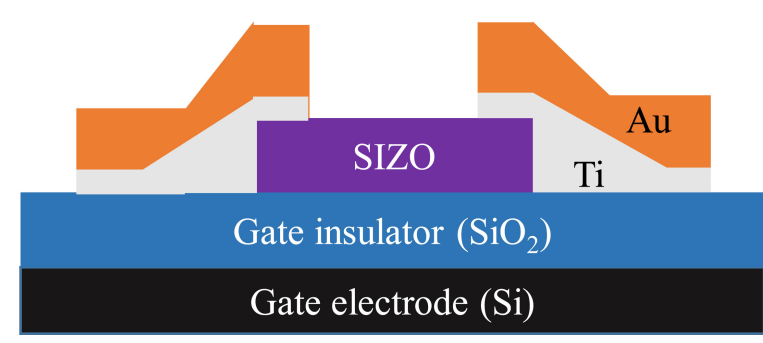

Fig. 1. Schematic diagram of the device with a bottom gate TFT structure with SIZO.

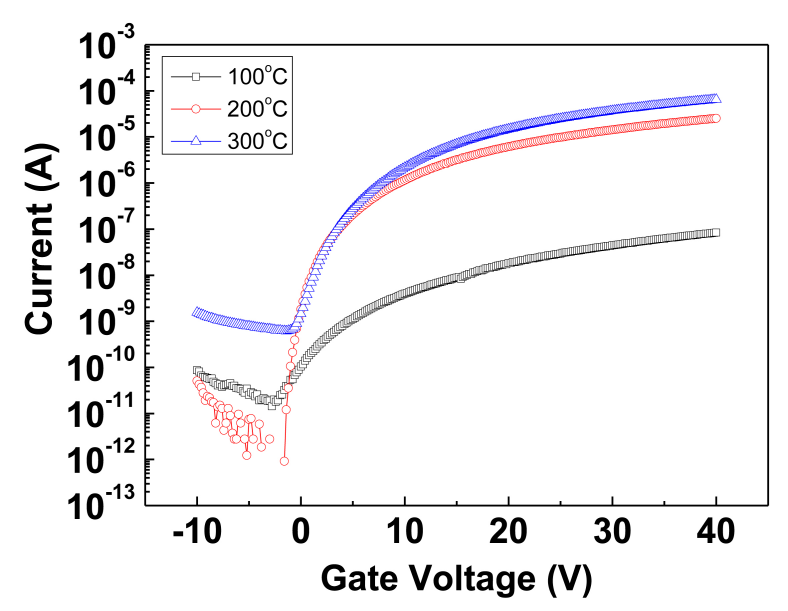

Fig. 2. Variation of drain current-gate voltage transfer curve with different temperature.

Table 1. The electrical characteristics, including threshold voltage, on-to-off ratio, $\mu_{\mathrm{FE}}$, and S.S of the SIZO TFTs.

\begin{tabular}{ccccc}
\hline Temperature & $\mathrm{V}_{\text {th }}(\mathrm{V})$ & $\begin{array}{c}\mathrm{I}_{\text {on/off }} \text { current } \\
\text { ratio }\end{array}$ & $\begin{array}{c}\mu_{\mathrm{FE}} \\
\left(\mathrm{cm}^{2} \mathrm{~V}^{-1} \mathrm{~S}^{-1}\right)\end{array}$ & $\begin{array}{c}\text { Subthreshold } \\
\text { swing } \\
(\mathrm{V} / \text { decade })\end{array}$ \\
\hline 100 & 7.0 & $5.9 \times 10^{3}$ & 0.009 & 2.51 \\
\hline 200 & 2.1 & $3.2 \times 10^{6}$ & 0.57 & 0.34 \\
\hline 300 & 2.2 & $1.1 \times 10^{5}$ & 1.37 & 1.46 \\
\hline
\end{tabular}

Where $\mathrm{C}_{\mathrm{i}}$ was the capacitance per unit area of the gate insulator, $\mathrm{W}$ and $\mathrm{L}$ were the channel width and length, $\mathrm{V}_{\mathrm{GS}}$ and $\mathrm{V}_{\text {th }}$ were the gate bias and the threshold voltage, respectively. The TFT performance parameters are summarized in Table 1 with different temperature, which include the field effect mobility $\left(\mu_{\mathrm{FE}}\right)$, the threshold voltage $\left(\mathrm{V}_{\mathrm{th}}\right)$, the on-current $\left(\mathrm{I}_{\mathrm{on}}\right)$, the carrier concentration, and the on-to-off current ratio $\left(\mathrm{I}_{\mathrm{on} / \mathrm{off}}\right)$. The electrical performance of SIZO was dependent on the annealing temperature. Field effect mobility was $1.37 \mathrm{~cm}^{2} \mathrm{~V}^{1} \mathrm{~s}^{-1}$ for $300^{\circ} \mathrm{C}$, whereas when temperature was decreased from 200 to $100^{\circ} \mathrm{C}$, the field effect mobility declined from 0.57 to $0.009 \mathrm{~cm}^{2} \mathrm{~V}^{1} \mathrm{~s}^{-1}$. The carrier concentration was calculated from the relation

$$
n=\frac{I_{D} L}{Q V_{D} \mu_{n} W d}
$$

where $\mathrm{n}$ is the carrier concentration, $\mathrm{I}_{\mathrm{D}}$ is the measured drain current at $V_{D}=5 \mathrm{~V}$ and $\mathrm{V}_{\mathrm{G}}=10 \mathrm{~V} \mathrm{~L}$ was the gate length, $\mathrm{W}$ was 


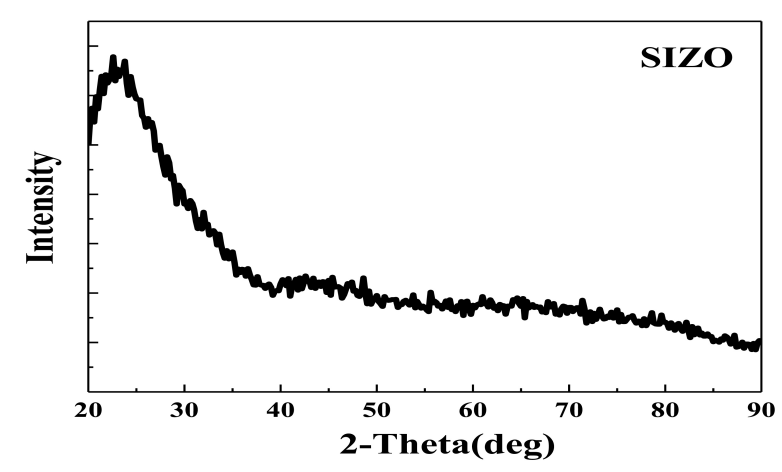

Fig. 3. XRD spectra of the solution processed SIZO layer at $300^{\circ} \mathrm{C}$

the channel width, $d$ was the gate insulator thickness, $q$ was the electron charge, and $\mu_{n}$ is the electron mobility. The resulting carrier concentrations were calculated at $10^{16} \mathrm{~cm}^{-3}$ with increasing temperature [14]. Figure 3 shows the XRD intensity of the SIZO film at $300{ }^{\circ} \mathrm{C}$. The SIZO revealed broad peak, which clearly indicates amorphous phase. Some metal cation elements in the active channel layer make an amorphous phase or prevent their columnar growth. Therefore, the metal elements act as a diffusion suppressor of ZnO-based TFTs, because they are heavy and slow in terms of diffusion $[15,16]$. The SIZO TFTs with increasing annealing temperature showed enhanced field effect mobility, indicating that carrier concentration was increased.

\section{CONCLUSIONS}

We have fabricated solution processed oxide TFTs based on SIZO at an annealing temperature of $300^{\circ} \mathrm{C}$ on electrical properties. When increasing annealing temperature, the formation of oxygen vacancy was increased due to generation of more electron carriers. As a result, mobility was increased, and $V_{\text {th }}$ shifted toward negative direction as the annealing temperature increased.

\section{ACKNOWLEDGMENT}

This work was supported by the research grant of Cheongju University in 2013, and this research was supported by the Cheongju University Research Scholarship Grants in 2014.

\section{REFERENCES}

[1] M. Kim, J. H. Jeong, H. J. Lee, T. K. Ahn, H. S. Shin, J. S. Park, J. K. Jeong, Y. G. Mo, and H. D. Kim, Appl. Phys. Lett., 90, 212114 (2007). [DOI: http://dx.doi.org/10.1063/1.2742790].

[2] S. H. K. Park, C. S. Hwang, J. I. Lee, S. M. Chung, Y. S. Yang, L. M. Do, and H. Y. Chu, SID Int. Symp. Digest Tech. Paper, 25 (2006).

[3] T. Hirao, M. Furuta, H. Furuta, T. Matsuda, T. Hiramatsu, H. Hokari, and M. Yoshida, SID Int. Symp. Digest Tech. Paper, 18 (2006).

[4] P. Barquinha, A. Pimentel, A. Marques, L. Pereira, R. Martins, and E. Fortunato, J. Non-Cryst. Solids., 352, 1749 (2006). [DOI: http://dx.doi.org/10.1016/j.jnoncrysol.2006.01.067].

[5] B. S. Kim, D. E. Kim, G. C. Choi, J. W. Park, B. J. Lee, and Y. S. Kwon, KIEE J. Electr. Eng. Technol., 4, 418 (2009). [DOI: http:// dx.doi.org/10.5370/JEET.2009.4.3.418].

[6] W. B. Jackson, R. L. Hoffman, and G. S. Herman, Appl. Phys. Lett., 87, 193503 (2005). [DOI: http://dx.doi.org/10.1063/1.2120895].

[7] J. J. Chen, M. H. Yu, W. L. Zhou, K. Sun, and L. M. Wang, Appl. Phys. Lett., 87, 173119 (2005). [DOI: http://dx.doi. org/10.1063/1.2119415].

[8] H. Q. Chiang, J. F. Wager, R. L. Hoffman, and C. H. Chang, Electrochem. Solid-State Lett., 10, H135 (2007). [DOI: http://dx.doi. org/10.1149/1.2666588].

[9] B. N. Pal, B. M. Dhar, K. C. See, and H. E. Katz, Nature Mater., 8, 898 (2009). [DOI: http://dx.doi.org/10.1038/nmat2560].

[10] S. Jeong, Y. G. Ha, J. Moon, A. Facchetti, and T. J. Marks, Adv. Mater., 22, 1346 (2010). [DOI: http://dx.doi.org/10.1002/ adma.200902450].

[11] R. Ghosh, G. K. Paul, and D. Basak, Mater. Res. Bull., 40, 1905 (2005). [DOI: http://dx.doi.org/10.1016/ j.materresbull.2005.06.010].

[12] K. Ogata, K. Sakurai, S. Fujita, S. Fujita, and K. Matsushige, J. Cryst. Growth., 312, 214 (2000).

[13] D. Kim, C. Y. Koo, K. Song, Y. Jeong, and J. Moon, Appl. Phys. Lett., 95, 103501 (2009). [DOI: http://dx.doi. org/10.1063/1.3225555].

[14] I. Abdel-Motaleb, N. Shetty, K. Leedy, and R. Cortez, J. Appl. Phys., 109, 014503 (2011). [DOI: http://dx.doi. org/10.1063/1.3525998].

[15] J. W. He, C. D. Bai, K. W. Xu, and N. S. Hu, Surf. Coat.Technol., 74, 387 (1995). [DOI: http://dx.doi.org/10.1016/02578972(95)08371-5].

[16] J. Y. Choi, S. Kim, and S. Y. Lee, Thin Solid Films, 520, 3774 (2012). [DOI: http://dx.doi.org/10.1016/j.tsf.2011.10.212]. 